\title{
Reuna
}

\section{RESPONSABILIDADE SOCIAL E QUALIDADE DE VIDA NO TRABALHO: A PERCEPÇÃO DE FUNCIONÁRIOS SUPERMERCADISTAS}

\author{
http://dx.doi.org/10.21714/2179-8834/2018v23n4p62-82
}

\author{
Tayna Boldo \\ Faculdade Meridional (IMED), Brasil. \\ E-mail: tayna_b_@hotmail.com \\ Eliana Andréa Severo \\ Universidade Potiguar (UNP), Brasil. \\ E-mail: elianasevero2@hotmail.com \\ Julio Cesar Ferro de Guimarães \\ Universidade Potiguar (UNP), Brasil. \\ E-mail: juliocfguimaraes@yahoo.com.br
}

Submissão: 20 Jun. 2018 Publicação: 31 Mai. 2019. Sistema de avaliação: Double blind review.

Centro Universitário UNA, Belo Horizonte - MG, Brasil. Editor geral: Prof. Dr. Gustavo Quiroga Souki

Este artigo encontra-se disponível nos seguintes endereços eletrônicos:

http://revistas.una.br/index.php/reuna/article/view/1033

http://dx.doi.org/10.21714/2179-8834/2018v23n4p62-82

\section{Resumo}

O objetivo desse estudo consiste em analisar a percepção dos colaboradores acerca da responsabilidade social, qualidade de vida no trabalho, os benefícios ofertados e a motivação, em uma empresa do ramo supermercadista, localizada no norte do Rio Grande do Sul. A metodologia tratou-se de pesquisa quantitativa e descritiva. Os resultados destacam que as ações sociais, benefícios ofertados e ações de qualidade de vida no trabalho são fatores relevantes à motivação e foram facilmente identificados pelos respondentes. Plano odontológico, salário justo e bons benefícios foram os itens com maior índice de concordância referente ao tema plano de benefícios. A pesquisa ainda identificou que somente o salário não é responsável por motivar um funcionário, mas sim um conjunto entre ações sociais e de qualidade de vida no trabalho, plano de benefícios, vida pessoal e realização organizacional.

Palavras-chave: Responsabilidade social; Qualidade de vida no trabalho; Benefícios; Motivação. 


\section{ABSTRACT}

The aim of this study is to analyze the employees' perception about the social responsibility, quality of life at work the benefits offered and the motivation, in a supermarket company located in the north of Rio Grande do Sul. The methodology was quantitative and descriptive research. The results of the study emphasize that the social, benefits offered and actions of quality of life at work are relevant factors to motivation and were easily identified by the respondents. Dental plan, fair salary and good benefits were the items with the highest agreement index referring to the theme of benefit plan. The research identified that only the salary is not responsible for motivating an employee, but rather a set of social actions and quality of life at work, benefits plan, personal life and organizational achievement.

Keywords: Social responsibility; Quality of life at work; Benefits; Motivation.

\section{Introdução}

As constantes mudanças econômicas, tecnológicas e sociais fazem parte do ambiente organizacional, no qual decisões e ações são tomadas em prol das empresas. O aumento da competitividade faz com que as organizações busquem novas maneiras de aperfeiçoar o seu microambiente, criando novas condições favoráveis de trabalho, para maximizar o crescimento e desenvolvimento dos colaboradores e da empresa. As ações sociais, qualidade de vida no trabalho (QVT) e a motivação são importantes fatores responsáveis por garantir um ambiente com condições saudáveis que contribuam para desenvolvimento econômico da organização (CARROL; SHABANA, 2010; SCHIRRMEISTER; FRANÇA, 2012; LUEG; PEDERSEN; CLEMMENSEN, 2015).

Para Carrol e Shabana (2010) a responsabilidade social visa a melhoria da QVT dos colaboradores. Coerentemente, emerge um elo que liga a responsabilidade social com a QVT, pois conforme Schirrmeister e França (2012) a QVT busca proporcionar ambiente de trabalho digno e agradável, com as mínimas condições físicas, psicológicas e sociais para os trabalhadores.

O setor de gestão de recursos humanos no decorrer da sua história sofreu grandes alterações. Também chamado de recursos humanos $(\mathrm{RH})$ ou de gestão de pessoas (GP), é a área responsável por desenvolver as ações sociais e a QVT nas organizações. Contudo, Inyang, Awa e Enuoh (2011) ressaltam que embora existam vários estudos sobre o tema, o papel da GP na área de responsabilidade social, ainda é pouco explorado. Nesse contexto, a área de GP torna-se fundamental no desenvolvimento de conceitos e práticas de responsabilidade social corporativa, podendo contribuir para a competitividade e performance organizacional (PFEFFER, 2010).

Nesse cenário, o setor de GP possui novas atribuições além de admissão e demissão de funcionários, sendo responsável também pela capacitação, desenvolvimento de plano de cargos e salários, carreira e benefícios, funções que bem administradas contribuem efetivamente na motivação do colaborador (DESSLER, 2003; VISCAINO; ESTORK, 2007; RODRIGUES; BARRICHELLO; MORIN, 2016). 
Altos índices de absenteísmo, rotatividade, insatisfação e falta de motivação com o trabalho são alguns dos principais motivos que levaram as empresas a repensarem na gestão e QVT dos seus colaboradores (VASCONCELOS et al., 2016). A motivação é elemento fundamental para o sucesso organizacional, é responsável por estimular os colaboradores a alcançarem seus objetivos e procurar maneiras de se desenvolver, a motivação ainda é considerada como um processo contínuo que precisa ser estimulada ao longo da vida, definida como intrínseca é resultante das necessidades internas, e para que ela seja atingida, é preciso que haja equilíbrio entre as necessidades primárias, são elas necessidades físicas, psicológicas e sociais (GIL, 2007; VERGARA, 2010; FERREIRA et al., 2016; PEDRO; SEVERO; CAPITANIO, 2016).

Na busca contínua de diferenciação e aperfeiçoamento dentro do setor de GP nas organizações, o estudo tem por objetivo analisar a percepção dos colaboradores de uma empresa supermercadista sobre a responsabilidade social e QVT, os benefícios ofertados e a motivação. Além dessa introdução, o artigo apresenta 0 referencial teórico elencando os temas de responsabilidade social, QVT, benefícios e motivação, metodologia utilizada, resultados e discussões e considerações finais.

\section{Referencial Teórico}

\section{2,1 Responsabilidade Social}

Segundo Carrol (1979) e Matten e Moon (2008) a compreensão da responsabilidade social corporativa é vista em duas dimensões: i) a responsabilidade social implícita, e, ii) a responsabilidade social explícita. Conforme os autores, a responsabilidade social implícita está alicerçada em sistemas mandatórios, em uma decisão reativa, de diretrizes legais e regulamentais por parte da organização, que definem as suas obrigações para com seus stakeholders. Entretanto, a responsabilidade social explícita está associada às políticas corporativas que visam o interesse da sociedade, refletindo políticas e práticas realizadas por iniciativa da empresa, tratando-se de uma atitude voluntária, deliberada, e até mesmo estratégica, por parte da organização.

Nas últimas duas décadas, a pesquisa sobre responsabilidade social vem sendo realizada nos países emergentes e em desenvolvimento, seguindo as práticas de relatórios dos respectivos negócios (FIFKA, 2013). A responsabilidade social das empresas abrange as expectativas econômicas, legais e éticas que a sociedade tem das organizações, fazendo do seu desempenho econômico e financeiro algo que não seja apenas para si, mas também para a sociedade (CARROLL, 1988; CARROL; SHABANA, 2010; SKUDIENE; AURUSKEVICIENE, 2012). Coerentemente, cada responsabilidade é apenas uma parte da responsabilidade social total da empresa (CARROLL, 1979; GARAY; FONT, 2012).

A responsabilidade social, por meio de suas normas e relatórios, como forma de transformar essas declarações em ações propriamente ditas, promovem benefícios, contribuindo para o desenvolvimento dos cidadãos, que podem ser alcançados pelas ações sociais, que além de beneficiarem a sociedade, protegem a natureza e procuram compensar os possíveis efeitos negativos da atuação da empresa (FORERO, 2011). 
Nesse contexto, a responsabilidade social pode estar atrelada tanto aos colaboradores, quanto a comunidade na qual a empresa está inserida, visando as questões ergonômicas e a melhoria da QVT dos funcionários (JAMALI, 2008; SABADIN; SEVERO; GUIMARÃES, 2017). Consoante isso, diferentes empresas desenvolvem ações sociais que beneficiam os funcionários, fornecedores e a comunidade (SARTOR et al., 2016; ZHU; LIU; LAI, 2016; PANDA; MODAK; CÁRDENAS-BARRÓN, 2017).

Por meio dessas ações, busca-se identificar causas e propor soluções para questões sociais como, por exemplo, saúde, assistência social, promoção da autoestima das pessoas, capacitação dos cidadãos, defesa dos direitos, envolvimento da comunidade, entre outros (ANHEIER, 2007; FOSTER, 2009; SILVA; AGUIAR, 2011; MINZNER et al., 2014).

\subsection{Qualidade de vida no trabalho}

De acordo com Albuquerque e Limongi (1998), a QVT pode ser descrita como um conjunto de ações que a empresa desenvolve utilizando um método de implantação de melhorias como inovações gerenciais, tecnológicas e estruturais, podendo ser dentro ou fora do ambiente de trabalho, visando oferecer boas condições de desenvolvimento humano durante a realização do trabalho.

A implantação da QVT nas organizações é resultado da intenção de proporcionar um ambiente de trabalho agradável para os colaboradores com as mínimas condições físicas, psicológicas e sociais, essa implantação além de atender as necessidades do colaborador, objetiva proporcionar a empresa resultados positivos, como o aumento da produtividade (SCHIRRMEISTER; FRANÇA, 2012; RIBEIRO; SANTANA, 2015).

Conforme Souza e Freitas (2009) e Alfenas e Ruiz (2015), a QVT está relacionada diretamente com o comprometimento pessoal, a participação com 0 bem-estar do colaborador nas tarefas da organização, objetivando metas da qualidade total. De acordo França et al. (2002), a QVT pode ser interpretada de diversas maneias, uma delas é descrita como um conjunto de ações desenvolvidas nas empresas com o objetivo de criar melhorias, inovações na gestão, melhorias tecnológicas e estruturais do ambiente organizacional.

Dentre as empresas que optam por vantagens competitivas, a QVT é indispensável pois a sua implementação garante o atendimento das expectativas dos colaboradores, satisfação pessoal e profissional, gerando retorno para as partes envolvidas (FREITAS; SOUZA, 2009).

Para Walton (1979), o objetivo de uma empresa que adota ações de QVT é a geração de uma organização mais humanizada, nesse contexto, o autor apresenta um dos modelos conceituais mais utilizados atualmente, o qual é formado por oito categorias que buscam analisar e descrever de forma completa a QVT nas organizações:

1) remuneração justa e adequada é forma de remuneração dos trabalhadores, a relação do cargo com o salário e busca a equidade salarial dentro do ambiente organizacional; 
2) segurança e condições saudáveis de trabalho é relacionada com a responsabilidade que a empresa tem com o colaborador em garantir um ambiente sem riscos que possam comprometer a saúde do colaborador;

3) utilização e desenvolvimento de capacidades objetiva oferecer ao trabalhador informações e oportunidades de desenvolver habilidades e perspectivas da atividade;

4) oportunidade de crescimento contínuo e segurança visa oferecer ao colaborador oportunidade de se desenvolver na organização e na carreira, está relacionado com as potencialidades, à realização dos deveres, ao exercício de aptidões, a organização e planejamento do trabalho;

5) integração social busca promover maneiras de comunicação aberta, democracia social, ascensão na carreira e incentivar as relações pessoais na organização, ausência de preconceito;

6) leis e normas promove a garantia o direito de privacidade e liberdade de expressão de ideias, respeito a individualidade de cada colaborador;

7) trabalho e espaço total de vida corresponde as condições de trabalho não devem atrapalhar no descanso e nem na vida pessoal do colaborador, deve respeitar a sua liberdade de expressão e os seus horários;

8) relevância social de vida no trabalho busca equilibrar os objetivos do colaborador com os da organização, a empresa deve atender as necessidades sociais dos indivíduos relacionados a saúde, comunicação, educação, transporte e higiene.

O modelo descrito por Walton (1973), mesmo escrito há mais de quarenta anos, no Brasil é o modelo mais utilizado para descrever a QVT, esse modelo é utilizado por diversos pesquisadores de administração e da psicologia organizacional (TOLFO et al., 2009; FREITAS; SOUSA, 2009; BARROS, 2012; RIBEIRO; SANTANA, 2015).

Para Gutierrez e Vilarta (2007) a QVT é descrita como uma gestão dinâmica e contingencial de fatores sociais, psicológicos, tecnológicos e físicos que interferem na cultura e clima organizacional da empresa e refletem diretamente no bem-estar do colaborador, na sua produtividade, e na sua motivação.

A gestão presente nas organizações que consideram fatores físicos, sociológicos, psicológicos e tecnológicos é capaz de oferecer um bom ambiente aos colaboradores da organização, essa preocupação com o trabalho torna-se saudável e propicia o aumento de produtividade refletindo no comportamento do colaborador no atendimento aos clientes e aos fornecedores (SOUZA; FREITAS, 2009; RIBEIRO; SANTANA, 2015).

O ambiente competitivo e a evolução constante são fatores que obrigam as empresas a buscarem estratégias diferenciadas no contexto econômico, portanto a implantação da QVT dentro das organizações é fundamental, pois além dos resultados positivos como motivação, melhora da produtividade e satisfação, ela garante o alinhamento dos objetivos da empresa com a do colaborador (FERREIRA et al., 2016; FRANÇA et al., 2002; SCHIRRMEISTER; FRANÇA, 2012; HATZENBERGER; CARLOTTO, 2013). 
O desenvolvimento das ações de QVT é de responsabilidade do gestor de pessoas, e cabe a ele considerar os aspectos de resolução dos problemas, reestruturação no sistema de remuneração e recompensas, melhoras no ambiente de trabalho, inclusão do colaborador na tomada de decisão, implementação de feedback e principalmente a ênfase no desenvolvimento humano, a partir dessas mudanças será possível observar diferenças no comportamento do trabalhador em relação ao comprometimento junto à organização (GIL, 2007; ALFENAS; RUIZ, 2015; ZWIELEWSKI; TOLFO, 2016).

\subsection{Benefícios}

É notório que diversas empresas buscam novas maneiras de aprimorar o seu sistema de gestão de pessoas, essa prática garante diversos benefícios, tanto para a empresa, quanto para o colaborador, dessa forma o investimento em plano de benefícios oferece aos trabalhadores uma melhoria na sua qualidade de vida, gerando satisfação e desempenho profissional (MOITINHO, 2011).

De acordo com Marras (2010), o plano de benefícios pode ser classificado em três conceitos: i) benefícios assistenciais: buscam promover saúde e segurança ao empregado podendo incluir ou não a sua família, bem como é oferecido em forma de assistência hospitalar, médica, serviço social, complemento a aposentadoria ou planos privados de previdência, seguro de vida, auxílio escola; ii) benefícios recreativos: clubes de lazer, áreas diferenciadas no intervalo de trabalho, música ambiente, atividades esportivas, passeios; e, iii) benefícios supletivos: transporte, restaurante local no trabalho, estacionamento no local de trabalho, horário móvel de trabalho e agência bancária no local de trabalho.

$\mathrm{Na}$ organização os benefícios refletem uma visão mais humana, relacionada com a QVT de seus colaboradores, melhoria do clima organizacional, redução da rotatividade, manutenção da gestão de pessoas e aumento da produtividade (GAULKE, NICOLETI, 2007; SANTOS et al., 2013).

Um dos objetivos do plano de benefícios é tornar a vida dos colaboradores mais agradável e humana, pois sem eles, os custos atrelados a alimentação, saúde entre outros teriam que ser diminuídos do salário, portanto benefícios são pagamentos financeiros indiretos pagos aos colaboradores em forma de plano de saúde, vale alimentação, custos com transportes e custos com educação (ARAUJO, 2006; GIL, 2007; MARRAS, 2010).

Nesse contexto, o plano de benefícios pode influenciar na melhoria da QVT, na redução de riscos de acidentes de trabalho, no aumento da produtividade e interação entre empresa e colaborador, redução do absenteísmo (faltas e atrasos), redução do turnover, isenção de encargos sociais sobre o valor ofertado, bem como incentivo fiscal (CHOI; SAITO; SILVA, 2015).

Para o trabalhador, o plano de benefícios proporciona além do atendimento a algumas necessidades básicas, o equilíbrio da qualidade de vida pessoal e organizacional, redução da fadiga física e psicológica, já para a empresa prima para a redução da rotatividade e absenteísmo, melhoria qualidade de vida, assim como minimiza o custo das horas trabalhadas (MARRAS, 2010). 
Segundo Wood Junior e Picareli Filho (2004), o plano de benefícios nas organizações podem assumir cinco tipologias: i) tradicional: seleção de conjunto de benefícios que serão ofertados aos colaboradores, distinção ocorre apenas no nível hierárquico, nessa forma o colaborador não possui opção de escolha; ii) flexibilização parcial: existe um pacote determinado de benefícios concedido pela empresa, mas o pacote pode ser complementado de acordo com as preferências do colaborador, e as escolhas são limitadas a níveis hierárquicos e faixa salarial; iii) modular: a empresa disponibiliza pacotes fechados de benefícios e os colaboradores tem a opção de escolher qual se enquadra melhor nas suas necessidades; iv) menu de opções: há uma relação de benefícios e seguindo as necessidades e preferencias pessoais, é limitada por critérios, nessa opção a empresa delimita o custo total do benefício e o colaborador escolhe como o pacote deve ser composto; e, v) escolha livre: o colaborador tem o poder de escolha dentro dos benefícios ofertados de acordo com o valor do custo determinado pela empresa.

A oferta por plano de benefícios muitas vezes é centralizada em empresas de médio e grande porte, ou seja, aquelas que possuem o setor de GP capaz de atender as necessidades dos colaboradores, e a sua implantação acarreta vantagens diretas e indiretamente, tanto para o colaborador, quanto para a empresa e a sociedade (WOOD Jr.; PICARELLI FILHO, 2004; SANTOS et al., 2013).

\subsection{Motivação}

Abrahan Maslow é um dos principais estudiosos que iniciou pesquisas na década de 1950, desenvolvendo estudos voltados a motivação, o autor aprofundouse nas necessidades humanas, classificando-as como primárias e secundárias (GOMES; QUELHAS, 2003; GIL, 2007; MARRAS, 2010; VERGARA, 2010; CAVALCANTE et al., 2015).

O processo motivacional elencado por Maslow organiza-se em forma de pirâmide, onde o ser humano precisa suprir as necessidades primárias, para sentirse motivado a buscar o suprimento das necessidades secundárias (GIL, 2007; MARRAS, 2010; VERGARA, 2010; CAVALCANTE et al., 2015). Coerentemente, a teoria motivacional de Maslow e a teoria de Herzberg são muito semelhantes, a diferença está em que Maslow considera cinco fatores responsáveis pela motivação: i) necessidades fisiológicas; ii) proteção e segurança; iii) necessidades sociais; iv) auto estima; e, v) auto realização. Já Herzber divide a motivação em apenas dois principais fatores: i) necessidades de higiene, na qual inclui os três primeiros fatores de Maslow; e, ii) satisfação, realização e reconhecimento do colaborador no ambiente de trabalho (VERGARA, 2010; CAVALCANTE et al., 2015).

Nesse contexto, as empresas são formadas por colaboradores, os quais podem proporcionar bons resultados, para os objetivos organizacionais. Para tanto, o trabalhador necessita de condições que favoreçam a sua motivação e satisfação, essas condições são de responsabilidade da empresa, pois permitirá um ambiente organizacional de qualidade elevando a produtividade e comprometimento (GIL, 2007; CARVALHO et al., 2013).

De acordo com Vergara (2005), a motivação é intrínseca, pois é originada do interior de cada pessoa, e são processos que envolvem sentimentos de continuidade, emoções, energias, forças, instintos que impulsionam os seres para 
alguma direção. A teoria da hierarquia das necessidades de Maslow, e da motivação de Herzberg, descrevem a motivação como intrínseca, considerando a motivação e a satisfação (GOMES; QUELHAS, 2003; MARRAS, 2010; NETO; MAZZA, 2015).

Os seres humanos são movidos pelos seus desejos e objetivos, a força interna que leva os seres a buscarem os objetivos é chamado motivação e é através dela que se busca suprir as necessidades intrínsecas e extrínseca (TAMAYO; PASCHOAL, 2003; GAULKE; NICOLETI, 2007).

A motivação no trabalho considera além das teorias propostas por diversos autores, as relações com remuneração, QVT, abordando condições físicas e psicológicas como responsáveis por desencadearem comportamentos ligados a motivação (GIL, 2007; CARVALHO et al., 2013).

\section{Metodologia de pesquisa}

O método utilizado nessa pesquisa é de caráter quantitativo e descritivo. A pesquisa quantitativa utiliza levantamento de dados quantitativos de pessoas ou de grupos para apresentar características e comportamentos de um determinado ambiente, o seu objetivo é medir, quantificar e interpretar com maior assertividade possível utilizando-se de métodos estatísticos como média, porcentagem e mediana (HAIR et al., 2010; MALHOTRA, 2012).

A quantificação e o tratamento dos dados através da estatística são etapas da pesquisa quantitativa que buscam um uma maior aproximação da exatidão, evitando possíveis distorções que podem levar a uma má interpretação dos resultados (MARCONI; LAKATOS, 2006). De acordo com Hair et al., (2010), a pesquisa descritiva baseia-se por meio da natureza do problema, da pergunta de pesquisa, e nos objetivos do estudo, pretendendo descrever características e situações de uma determinada população, identificando a relações entre as variáveis propostas.

A pesquisa realizou-se em uma das unidades da empresa supermercadista, a qual está localizada na região norte do Rio Grande do Sul. A unidade onde aplicouse a pesquisa possui 110 colaboradores distribuídos em diversas áreas de atuação, como caixas, supervisores e gerentes. Nesse contexto, a população da unidade escolhida apresenta 110 colaboradores. De acordo com Malhotra (2012), população é a soma dos elementos que constituem alguma semelhança entre si, já amostra é um uma parte da população selecionada para aplicação do estudo. Dentre as duas de técnicas de amostragem probabilística e não probabilística, a amostra do presente estudo classifica-se em não probabilística, por conveniência, visto que os respondentes não foram selecionados a partir de algum critério estatístico, e por conveniência, pois é o método de amostragem permite ao pesquisador coletar dados por conveniência de acordo com a sua disponibilidade e escolha (MARCONI; LAKATOS, 2006; HAIR et al., 2010). Nesse estudo a escolha da técnica de amostragem não probabilística justifica-se devido ao pesquisador poder aplicar a pesquisa em uma unidade, de acordo com a indicação da empresa pela unidade de pesquisa, a disponibilidade de tempo do pesquisador e a facilidade de acesso a amostra. Portanto, a amostra foi constituída por 56 colaboradores. 
Para a coleta de dados, a técnica definida foi a elaboração de um questionário. De acordo com Malhotra (2012) trata-se de um método que objetiva coletar dados específicos da amostra baseando-se na aplicação de um questionário estruturado. A aplicação do questionário ocorreu pessoalmente, em horário comercial agendado antecipadamente com o supervisor, nos dias 24/04/2017 e 25/04/2017. Coerentemente, elaborou-se um questionário com uma escala intervalar Likert de 5 pontos, que variam de discordo totalmente a concordo totalmente. $O$ questionário apresenta três construtos divididos entre as áreas de benefícios, responsabilidade social e QVT, e motivação, contendo um total de 22 questões (Quadro 1). Destaca-se que o questionário passou pela validação de um Doutor expert na área temática estudada.

Quadro 1 - Construtos da pesquisa

\begin{tabular}{|c|c|c|}
\hline \multicolumn{3}{|c|}{ Construto: Benefícios } \\
\hline Sigla & Questões & Autores \\
\hline B1 & $\begin{array}{l}\text { Estou satisfeito com os benefícios ofertados pela empresa? } \\
\text { Ex. (vale alimentação, plano de saúde, etc.) }\end{array}$ & \multirow{6}{*}{$\begin{array}{l}\text { Adaptado dos } \\
\text { estudos de Wood } \\
\text { Junior e Picareli } \\
\text { Filho (2004), Gil } \\
\text { (2007), Marras } \\
\text { (2010), Vergara } \\
\text { (2010), Assalin e } \\
\text { Aranha (2010), } \\
\text { Santos et al. (2013), } \\
\text { Choi, Saito e Silva } \\
\text { (2015). }\end{array}$} \\
\hline B2 & Acho importante plano de saúde como benefício. & \\
\hline B3 & Acho importante plano odontológico como benefício. & \\
\hline B4 & $\begin{array}{l}\text { Acredito que salário justo e bons benefícios ajudam na } \\
\text { qualidade de vida. }\end{array}$ & \\
\hline B5 & $\begin{array}{l}\text { Acredito que um salário justo e bons benefícios ajudam na } \\
\text { motivação. }\end{array}$ & \\
\hline B6 & Acho meu salário justo em relação a função que desempenho. & \\
\hline \multicolumn{3}{|c|}{ Construto: Responsabilidade social e QVT } \\
\hline Sigla & Questões & Autores \\
\hline Q7 & $\begin{array}{l}\text { Para mim é importante que a empresa possua ações de } \\
\text { qualidade de vida no trabalho. }\end{array}$ & \multirow{8}{*}{$\begin{array}{l}\text { Adaptado dos } \\
\text { estudos de Walton } \\
\text { (1973), Fernandes } \\
\text { (1996), França et } \\
\text { al., (2002), Wood Jr } \\
\text { e Picarelli Filho } \\
\text { (2004), Gil (2007) } \\
\text { Schirrmeister e } \\
\text { França (2012), } \\
\text { Hatzenberger e } \\
\text { Carlotto (2013), } \\
\text { Alfenas e Ruiz } \\
\text { (2015), Madureira } \\
\text { (2015), Ribeiro e } \\
\text { Santana (2015). }\end{array}$} \\
\hline Q8 & Me sinto realizado na empresa. & \\
\hline Q9 & $\begin{array}{l}\text { Para mim ter qualidade de vida no trabalho é quando a } \\
\text { organização oferece segurança e estabilidade para seus } \\
\text { colaboradores. }\end{array}$ & \\
\hline Q10 & $\begin{array}{l}\text { Para mim ter qualidade de vida no trabalho é quando a } \\
\text { organização tem uma preocupação com a saúde de seus } \\
\text { colaboradores. }\end{array}$ & \\
\hline Q11 & O meu trabalho está em sintonia com a minha vida pessoal. & \\
\hline Q12 & $\begin{array}{l}\text { Para mim ter qualidade de vida no trabalho é quando a } \\
\text { organização disponibiliza área de lazer para ser utilizada nos } \\
\text { intervalos dos colaboradores. }\end{array}$ & \\
\hline Q13 & $\begin{array}{l}\text { Para mim um ambiente de trabalho com qualidade de vida } \\
\text { aumenta o meu comprometimento }\end{array}$ & \\
\hline Q14 & $\begin{array}{l}\text { Para mim ter qualidade de vida no Trabalho é quando a } \\
\text { organização investe na carreira dos seus colaboradores. }\end{array}$ & \\
\hline
\end{tabular}


Quadro 1 - Construtos da pesquisa (continuação)

\begin{tabular}{|c|c|c|}
\hline \multicolumn{3}{|c|}{ Construto: Motivação } \\
\hline Sigla & Questões & Autores \\
\hline M15 & $\begin{array}{l}\text { Minhas necessidades físicas, como comida, moradia, lazer } \\
\text { são supridas. }\end{array}$ & $\begin{array}{l}\text { Adaptado dos } \\
\text { estudos de Gomes }\end{array}$ \\
\hline M16 & Me sinto seguro sobre a minha estabilidade no meu emprego. & e Quelhas (2003), \\
\hline M17 & Tenho bom relacionamento com a minha família & Gaulke e Nicoleti \\
\hline M18 & Me sinto reconhecido no ambiente de trabalho. & (2007), Vergara \\
\hline M19 & Me sinto realizado no trabalho. & (2010), Carvalho et \\
\hline M20 & $\begin{array}{l}\text { A possibilidade de ter um plano de carreira aumenta a minha } \\
\text { motivação. }\end{array}$ & \\
\hline M21 & $\begin{array}{l}\text { Me sinto motivado para trabalhar apenas considerando salário } \\
\text { que a empresa oferece. }\end{array}$ & $\begin{array}{l}\text { (2015), Madureira } \\
\text { (2015), Pedro, }\end{array}$ \\
\hline M22 & $\begin{array}{l}\text { Me sinto motivado a trabalhar pelas condições de qualidade } \\
\text { de vida que a empresa oferece. }\end{array}$ & $\begin{array}{l}\text { Severo e C } \\
(2016)\end{array}$ \\
\hline
\end{tabular}

Fonte: Elaborado pelos autores (2019).

Para serem analisados, os dados coletados passaram pelos processos de seleção, onde foram avaliados e detectados possíveis falhas ocorrendo a tabulação, assim os foram dispostos em tabelas, facilitando a verificação e análise (MARCONI; LAKATOS, 2006). A técnica de análise de dados utilizada para esse estudo elencou a estatística descritiva. Para Malhotra (2012) a estatística descritiva é utilizada para transcrever os dados de uma determinada amostra utilizando os dois tipos de medidas, como medidas de tendência central e medidas de disperção. Nesse contexto, utlizou-se a média e o desvio-padrão para a análise dos resultados.

\section{Discussão dos resultados}

No estudo obteve-se uma amostra de 56 respondentes, onde $27(48,2 \%)$ são do gênero masculino e $29(51,8 \%)$ correspondem ao gênero feminino. A faixa de idade predominante, foi de 18 a 25 anos, totalizando 33 respondentes $(58,9 \%)$, e de 26 a 40 anos tem-se 17 respondentes (30,4\%), já de 41 a 60 anos 4 respondentes $(7,1 \%)$.

De acordo com o Gráfico 1, no que tange a escolaridade, destaca-se que 21 respondentes $(37,5 \%)$ possuem ensino médio completo, 13 respondentes $(23,2 \%)$ possuem superior incompleto, e apenas 3 respondentes $(5,4 \%)$ possuem ensino superior completo. 
Gráfico 1 - Escolaridade dos respondentes

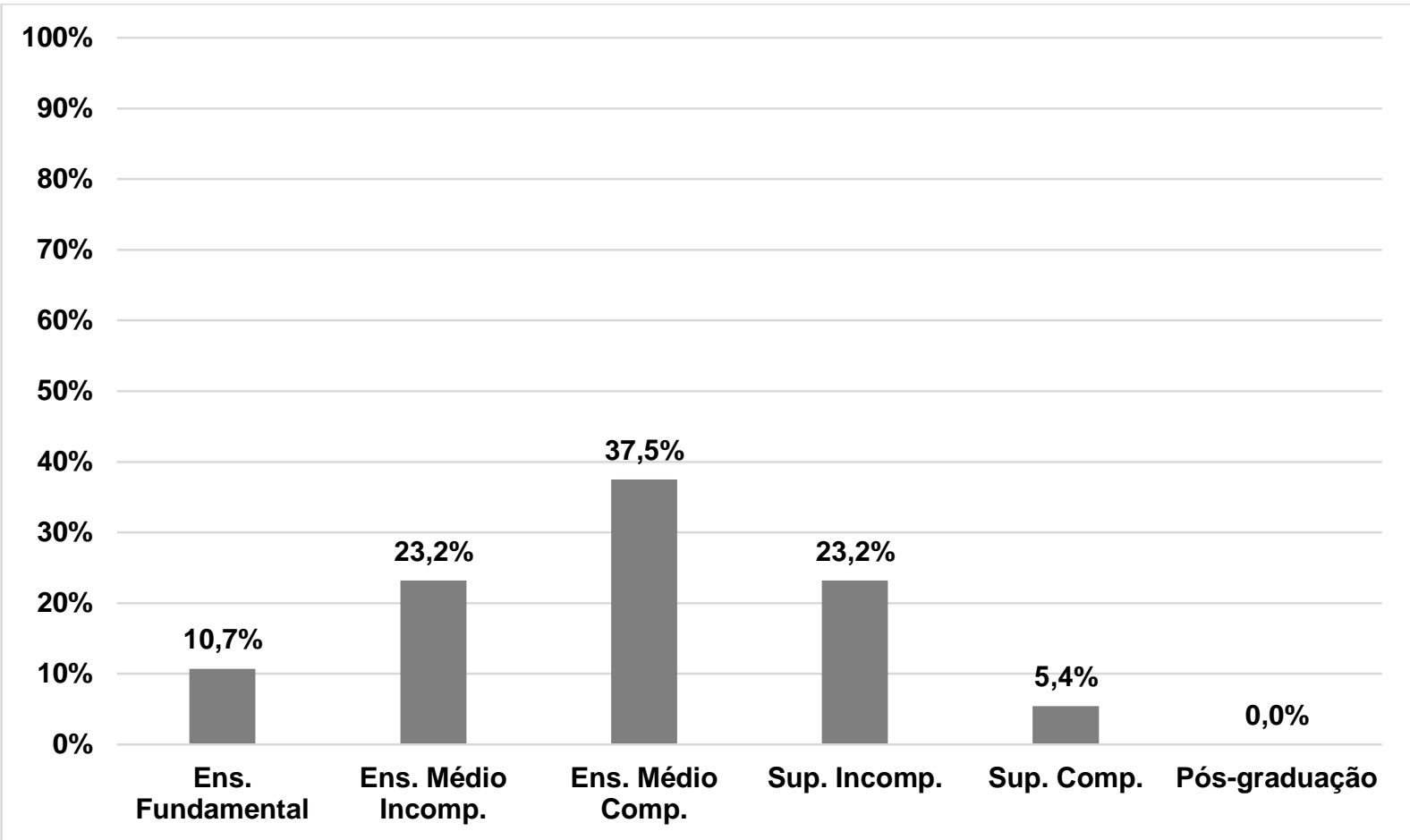

Fonte: Elaborado pelos autores (2019).

O item renda do funcionário foi subdividido em três faixas, 22 respondentes $(39,3 \%)$ recebem 1 salário mínimo, de 1 a 3 salários mínimos têm-se 33 respondentes (58,9\%), acima de 3 salários mínimos apenas 1 respondente $(1,8 \%)$. Nesse cenário, observa-se que apenas um colaborador recebe remuneração superior a três salários mínimos, esse fator deve-se a pesquisa ter sido aplicada em uma empresa supermercadista, o que nos dias atuais, a remuneração dos colaboradores do setor ainda é considerada baixa, entretanto, a pessoa que recebe esse salário está atrelada a área de gestão.

\subsection{Percepção sobre os benefícios}

No instrumento de coleta desenvolvido, os temas foram divididos em três blocos, sendo o primeiro referente a benefícios e remuneração. A Tabela 1 apresenta os resultados para o Bloco 1, evidenciando as respostas agrupadas em dois grupos, sendo no primeiro grupo (1, 2 e 3) e no segundo grupo (4 e 5), a partir da escala Likert de 5 pontos. A divisão desses dois grupos demonstra a quantidade de discordância (1 a 3) e concordância (4 e 5) em relação as questões.

Quanto aos benefícios e remuneração ofertados pela empresa supermercadista, destaca-se a questão B4 "Acredito que ter salário justo e bons benefícios ajudam na qualidade de vida", onde $96,4 \%$ dos respondentes concordaram totalmente ou parcialmente com a afirmação, apresentando uma média de 4,8 e um desvio padrão de 0,532. Nas empresas o cuidado em oferecer uma remuneração que está atrelada com a função desempenhada reflete que a 
organização segue os preceitos básicos da boa gestão de pessoas, bem como está preocupada com a qualidade de vida dos seus colaboradores (RIBEIRO; CARVALHO et al., 2013; RIBEIRO; SANTANA, 2015).

A questão B6 "Acho meu salário justo em relação a função que desempenho", também destacou-se por apresentar o menor percentual e desvio padrão em relação às outras questões do mesmo bloco, sendo que $62,5 \%$ concordam totalmente ou parcialmente com a afirmação.

Tabela 1 - Benefícios e remuneração

\begin{tabular}{l|c|c|c|c|c}
\hline \multicolumn{1}{c|}{ Bloco 1 } & $\mathbf{1 , 2}$ e 3 & 4 e 5 & \% de 4 e 5 & Média & Desvio Padrão \\
\hline B1 & 22 & 34 & $60,7 \%$ & 3,4 & 1,410 \\
\hline B2 & 9 & 47 & $83,9 \%$ & 4,4 & 0,846 \\
\hline B3 & 9 & 47 & $83,9 \%$ & 4,4 & 0,843 \\
\hline B4 & 2 & 54 & $96,4 \%$ & 4,8 & 0,532 \\
\hline B5 & 3 & 53 & $94,6 \%$ & 4,8 & 0,738 \\
\hline B6 & 21 & 35 & $62,5 \%$ & 3,4 & 1,399 \\
\hline Média & & & $\mathbf{8 0} \%$ & $\mathbf{4 , 2}$ & $\mathbf{0 , 9 6 1}$ \\
\hline
\end{tabular}

Fonte: Elaborado pelos autores (2019).

De acordo com o Gráfico 2 ocorreu uma alta incidência de concordância com as questões do Bloco 1, deixando explícito que os participantes, em sua maioria, consideram plano de saúde, plano odontológico, salário justo e bons benefícios importantes na composição remuneração total. Para Choi, Saito e Silva (2015), o pacote de benefícios faz parte da remuneração indireta dos colaboradores e serve como ajuda e incentivo ao colaborador.

Grafico 2 - Benefícios ofertados (Bloco 1 - responderam 4 ou 5)

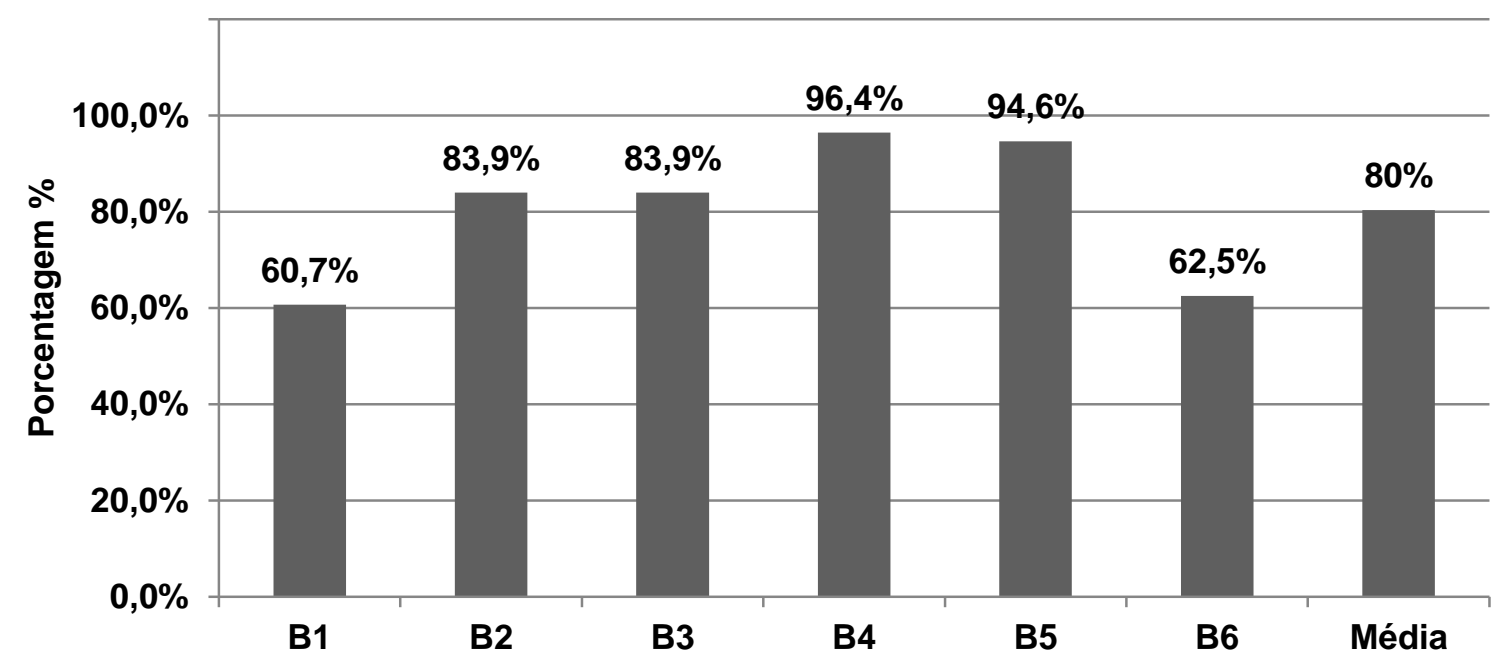

Fonte: Elaboração própria (2019).

REUNA, Belo Horizonte - MG, Brasil, v.23, n.4, p.62-82, Dut. - Dez. 2018 - ISSN 2179-88344 


\subsection{Percepção sobre a responsabilidade social e a QVT}

Os resultados acerca das ações sociais e QVT aplicado de acordo com o Bloco 2 (Tabela 2) ressaltam duas questões com os maiores percentuais, sendo a questão Q13 "Para mim um ambiente de trabalho com qualidade de vida aumenta o meu comprometimento" e a questão Q14 "Para mim ter qualidade de vida no trabalho é quando a organização investe na carreira dos seus colaboradores", totalizando um percentual de concordância de 98,2\% apresentado no Gráfico 5, bem como uma média de 4,6 com desvio padrão de 0,444.

Tabela 2 - Responsabilidade social e QVT

\begin{tabular}{l|c|c|c|c|c}
\hline Bloco2 & $\mathbf{1 , 2}$ e 3 & $\mathbf{4}$ e 5 & \% & Média & Desvio Padrão \\
\hline $\mathbf{Q 7}$ & 4 & 52 & $92,9 \%$ & 4,6 & 0,731 \\
\hline $\mathbf{Q 8}$ & 21 & 35 & $62,5 \%$ & 3,6 & 1,227 \\
\hline $\mathbf{Q 9}$ & 7 & 49 & $87,5 \%$ & 3,6 & 1,227 \\
\hline $\mathbf{Q 1 0}$ & 3 & 53 & $94,6 \%$ & 3,6 & 1,227 \\
\hline $\mathbf{Q 1 1}$ & 22 & 34 & $60,7 \%$ & 3,6 & 1,227 \\
\hline $\mathbf{Q 1 2}$ & 14 & 42 & $75,0 \%$ & 4,3 & 0,993 \\
\hline Q13 & 1 & 55 & $98,2 \%$ & 4,6 & 0,590 \\
\hline Q14 & 1 & 55 & $98,2 \%$ & 4,8 & 0,444 \\
\hline Média & & & $\mathbf{8 4 \%}$ & $\mathbf{4 , 1}$ & $\mathbf{0 , 9 5 8}$ \\
\hline
\end{tabular}

Fonte: Elaboração própria (2019).

Nesse contexto, acerca da QVT, a questão Q11 "O meu trabalho está em sintonia com a minha vida pessoal" de acordo com o Gráfico 3 apresentou o menor percentual de concordância, sendo 60,7\%. Estes resultados indicam que os colaboradores estão visualizando a que a QVT está sendo preconizada pela empresa, pois de acordo com Walton (1973), um dos fatores da QVT é a relevância social, a qual descreve que o colaborador precisa estar em equilíbrio no trabalho e na vida social (TOLFO; PICCININI; PEDROSO; PILLATI; 2009; FREITAS; SOUSA, 2009; BARROS, 2012; RIBEIRO; SANTANA, 2015).

A QVT é um conjunto de características que estão preocupados com a saúde, qualidade, satisfação dos colaboradores, quando o colaborador se sente insatisfeito com o salário atrelado a função desempenhada, é possível que o seu rendimento e o seu comprometimento sejam afetados (ZWIELEWSKI; TOLFO, 2016). 
Gráfico 3 - Responsabilidade social e QVT (Bloco 2 - Responderam 4 ou 5)

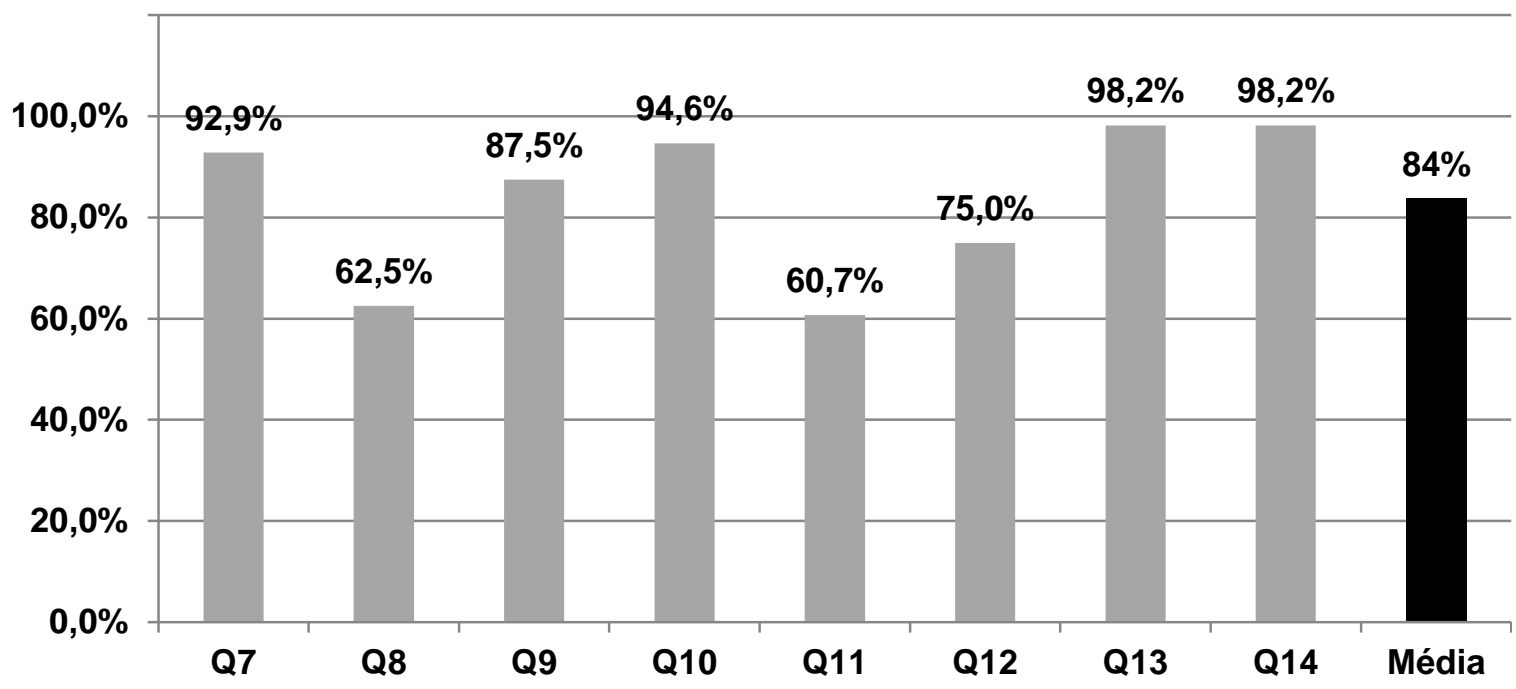

Fonte: Elaboração própria (2019).

\subsection{Percepção sobre a motivação no plano de benefícios e QVT}

Os resultados acerca do tema motivação, apresentado na Tabela 3 e relacionados a plano de benefícios e QVT no Bloco 3 (Gráfico 6) demonstram na questão M17 "Tenho bom relacionamento com a minha família" o maior percentual, sendo de $98,2 \%$ de concordância, tendo uma média de 4,8 e um desvio padrão de 0,444 . De acordo com a pirâmide das necessidades de Maslow, a motivação é formada por cinco fatores, sendo um deles relacionado a necessidades sociais onde - ser humano necessita de equilíbrio emocional oriundo da família, amigos e parceiros (GIL, 2007; MARRAS, 2010; VERGARA, 2010; NETO; MAZZA, 2015).

Tabela 3 - Motivação

\begin{tabular}{l|c|c|c|c|c}
\hline $\begin{array}{c}\text { Bloco 3 } \\
\text { Motivação }\end{array}$ & $\mathbf{1 , 2}$ e 3 & $\mathbf{4}$ e 5 & $\%$ & Média & Desvio Padrão \\
\hline M15 & 11 & 45 & $80,4 \%$ & 4,0 & 1,198 \\
\hline M16 & 12 & 44 & $78,6 \%$ & 4,1 & 1,180 \\
\hline M17 & 1 & 55 & $98,2 \%$ & 4,8 & 0,444 \\
\hline M18 & 16 & 40 & $71,4 \%$ & 3,6 & 1,397 \\
\hline M19 & 18 & 38 & $67,9 \%$ & 3,6 & 1,409 \\
\hline M20 & 6 & 50 & $89,3 \%$ & 4,5 & 1,027 \\
\hline M21 & 31 & 25 & $44,6 \%$ & 3,7 & 1,303 \\
\hline M22 & 18 & 38 & $67,9 \%$ & 3,7 & 1,303 \\
\hline Média & & & $\mathbf{7 5 \%}$ & $\mathbf{4 , 0}$ & $\mathbf{1 , 1 5 8}$ \\
\hline
\end{tabular}

Fonte: Elaboração própria (2019). 
A questão M21 "Me sinto motivado para trabalhar considerando somente o salário que a empresa oferece" obteve a menor porcentagem de concordância com somente 44,6\%, bem como uma média de 3,7 e desvio padrão de 1,303 demonstrando que nessa pesquisa, a remuneração como fator isolado não colabora com a motivação do colaborador. Coerentemente, a remuneração possui extrema importância no relacionamento organização e colaborador, mas somente ela não é capaz de satisfazer as necessidades motivacionais dos seres humanos (WOOD Jr.; PICARELLI FILHO, 2004; OLIVEIRA et al., 2014).

Estudos atuais já demonstram quão importante é a organizações abrangerem outros fatores relacionados a motivação e deixar de focar somente na remuneração como fator único de motivação. De acordo com as teorias de motivação de Maslow e Herzberg a motivação é oriunda de um conjunto de fatores (MARRAS, 2010; VERGARA, 2007; CAVALCANTE et al., 2015).

No Gráfico 4, pode-se visualizar com clareza as diferenças de percentuais acerca das questões com maiores diferenças de concordância, sendo que a questão M 17 "Tenho bom relacionamento com a minha família" apresentou o maior percentual, e a questão M 21 "Me sinto motivado para trabalhar considerando somente o salário que a empresa oferece" apresentou o menor percentual sendo $44,6 \%$.

Gráfico 4 - Motivação (Bloco 3 - responderam 4 ou 5)

\section{Bloco 3 Motivação - Responderam 4 ou 5}

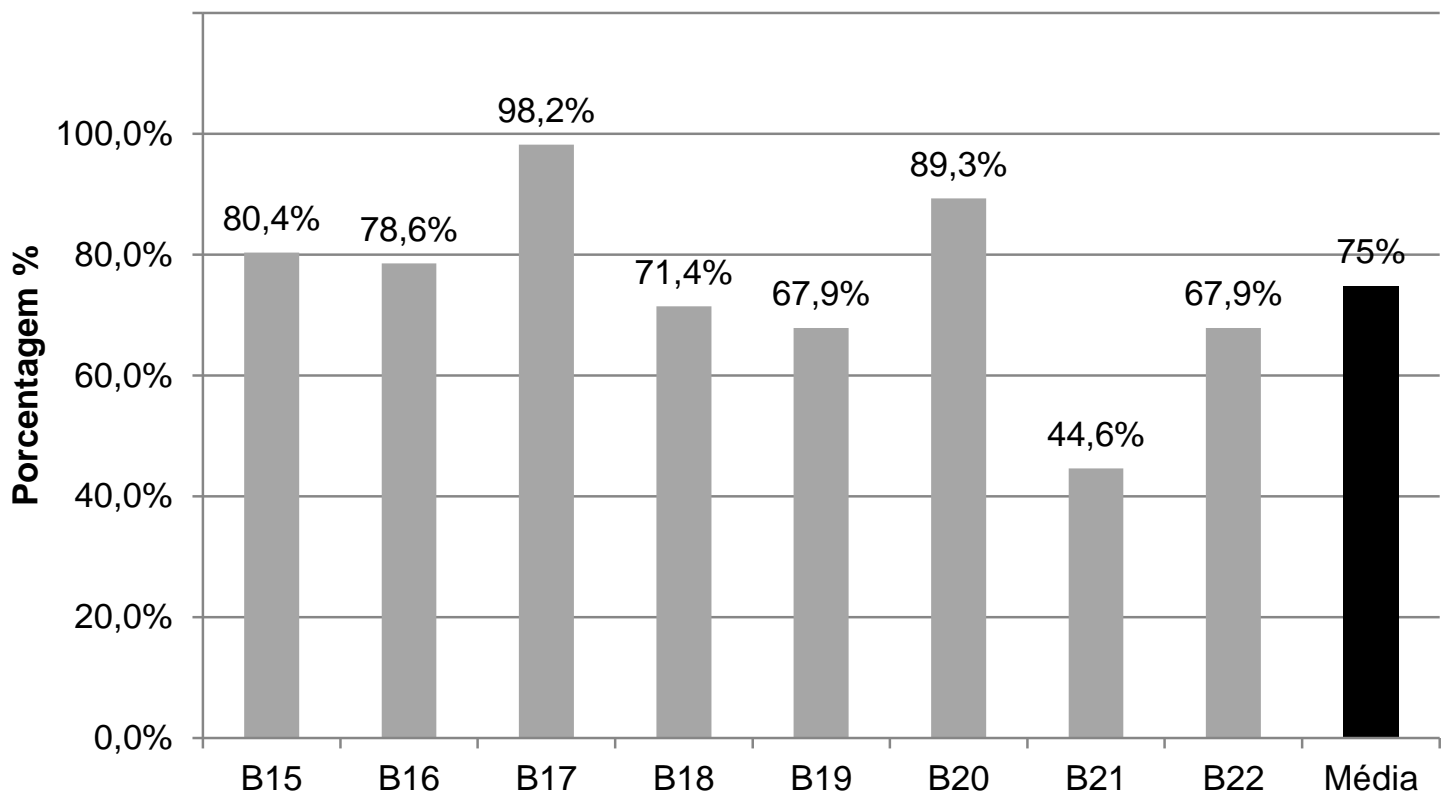

Fonte: Elaborado pelos autores (2019). 


\section{Considerações finais}

A percepção dos colaboradores sobre os benefícios e remuneração ressaltam que a maioria dos respondentes, $96,4 \%$ consideram a remuneração e benefícios como fatores importantes para a QVT, corroborando com estudos de Gil (2007), Santana (2015), Carvalho et al. (2013) e Choi, Saito e Silva (2015), no qual destacam que esses fatores colaboram para a QVT, associando a remuneração e benefícios ao reconhecimento pelo trabalho prestado.

No que tange a percepção dos colaboradores acerca das ações sociais e de QVT, os achados da pesquisa destacam que $98,2 \%$ dos respondentes consideram que um ambiente com QVT aumenta o comprometimento, o resultado ainda mostra que $98,2 \%$ dos respondentes concordam que QVT é quando a organização investe na carreira dos colaboradores.

Nesse cenário, a QVT relaciona-se diretamente com o comprometimento, visto que quando a empresa mostra preocupação com o colaborador, considerando também o plano de carreiras, o mesmo tende a desenvolver um alto grau de comprometimento para com a organização (SOUZA; FREITAS, 2009; MADUREIRA, 2015; RIBEIRO; SANTANA, 2015).

No que se refere como os benefícios e a QVT influenciam na motivação, destaca-se que $44,6 \%$ dos colaboradores não se sentem motivados considerando somente a variável remuneração. Contudo, $67,9 \%$ dos colaboradores demonstram que houve pouca concordância referente somente ao tema QVT, demonstrando que os colaboradores não consideram a motivação analisando individualmente os temas, mas sim um conjunto de ações que colaboram com a motivação. Consoante isso, a motivação é percebida como intrínseca, portanto o ambiente externo, apenas influenciará no comportamento dos seres, mas não pode motivá-los totalmente (TAMAYO; PASCHOAL, 2003), pois a motivação humana, tende a ser obtida por meio de vários fatores, como atendimento das necessidades físicas, psicológicas e emocionais (GOMES; QUELHAS, 2003; VERGARA, 2005; MARRAS, 2010; CARVALHO et al., 2013; CAVALCANTE et al., 2015).

Nesse cenário, a motivação existe a partir do momento da satisfação de alguma necessidade humana, seja ela fisiológica, de segurança, social, estima e realização, bem como a motivação relaciona-se com o reconhecimento, realização, satisfação, crescimento profissional, remuneração justa e condições ambientais adequadas (GIL, 2007; MARRAS, 2010; VERGARA, 2005).

Por fim, conclui-se a motivação não está associada a uma variável isolada, mas sim a um conjunto de fatores associados às condições de trabalho, QVT, remuneração e benefícios. Considerando as contribuições acadêmicas, destaca-se os construtos utilizados nesta pesquisa, poderão serem utilizados por outros pesquisadores, bem como para analisar outros setores e organizações. A contribuição gerencial é favorável aos profissionais de GP que buscam estratégias nas tomadas de decisões, objetivando a preocupação com a saúde e bem estar do colaborador. 
No que tange as limitações do estudo, elenca-se a empresa escolhida para desenvolvimento do estudo, pois a mesma é considerada de grande porte, na qual a pesquisa foi aplicada somente em uma das unidades. Portanto, representa a realidade da unidade envolvida. Outra limitação encontrada foi quanto a coleta de dados, visto que nem todos os colaboradores puderam comparecer em função de estarem de férias, folga ou se ausentarem para a realização da pesquisa.

Para próximos estudos sugere-se uma maior amostra, juntamente com aplicação da pesquisa em outras unidades da empresa para a obtenção de uma visão sistêmica em torno da organização. Outros temas podem ser correlacionados, tais como o clima organizacional e o comprometimento. Sugere-se também uma análise mais abrangente, comparando diferentes setores, bem como as temáticas em diferentes organizações e regiões do país.

\section{Referências}

ALBUQUERQUE, L. G.; LIMONGI-FRANÇA, A. C. Estratégias de recursos humanos e gestão da qualidade de vida no trabalho: o stress e a expansão do conceito de qualidade total. Revista de Administração, v. 33, n. 2, p. 40-51, 1998.

ALFENAS, R. A. da S.; RUIZ, V. M. Um Panorama de estudos sobre qualidade de vida no trabalho na administração pública brasileira no período de 2007 a 2013. Revista Organizações em Contexto, v. 11, n. 22, p. 143-167, 2015.

ANHEIER, H. K. Reflections on the concept and measurement of global civil society. Voluntas, v. 18, n. 1, p. 1-15, 2007.

ARAÚJO, L. C. Gestão de Pessoas: estratégias e interação organizacional. São Paulo: Atlas, 2006.

BARROS, S. P. Os discursos sobre qualidade de vida para os trabalhadores enquanto

Mecanismos disciplinares. Cadernos de Psicologia Social do Trabalho, v. 15, n.1, p.17-32, jun. 2012.

CARROLL, A. B. A three-dimensional conceptual model of corporate performance. Academy of Management Review, v. 4, n. 4, p. 497-505, 1979.

CARROLL, A. B. The four faces of corporate citizenship. Business and Society Review, v. 100, n. 101, p. 1-7, 1998.

CARROLL, A. B.; SHABANA, K. M. The business case for corporate social responsibility: a review of concepts, research and practice. International Journal of Management Reviews, 2010.

CHOI, D. Y.; SAITO, R.; SILVA, V. A. B. Estrutura de capital e remuneração dos funcionários: Evidência empírica no Brasil. Revista de Administração Contemporânea, v .19, n. 2, p. 250-269, 2015. 
CARVALHO, J. F.; MARTINS, E. P. T.; LÚCIO, L.; PAPANDREA, P. J. Qualidade de vida no trabalho e fatores motivacionais dos colaboradores nas organizações. Educação em Foco, v. 9, n. 7, p. 21-31, 2013.

CAVAlCANTE, C. E.; SOUZA, W. J.; MOL, A. L. R.; PAIVA, J. A. Motivação para entrada de voluntários em ONG brasileira. Revista de Administração, v. 50, n.4, p. 523-540, 2015.

DESSLER, G. Administração de recursos humanos. São Paulo: Prentice Hall, 2003.

FERREIRA, C.A.A.; REIS NETO, M.T.; VASCONCELOS, F.C.W.; SOUKI, G.Q. Motivation and rewards to health professionals. Gestão e Planejamento. v.17, p.41 58, 2016.

FIFKA, M. S. Corporate responsibility reporting and its determinants in comparative perspective-a review of the empirical literature and a meta-analysis. Business Strategy and the Environment, v. 22, n. 1, p. 1-35, 2013.

FORERO, G. A. V. Responsabilidad social empresarial, ciudadanía y desarrollo. Cuadernos de Administración: Serie de Organizaciones, v. 24, n. 43, p. 177-191, 2011.

FOSTER, M. K.; MEINHARD, A. G.; BERGER, I. E.; KRPAN, P. Corporate philanthropy in the Canadian context from damage control to improving society. Nonprofit and Voluntary Sector Quarterly, v. 38, n. 3, p. 441-466, 2009.

FRANÇA, A. C. L.; FISCHER, A. L.; NOGUEIRO, A.; DUTRA, J. S.; ALBUQUERQUE, L.; FLEURY, M. T.; EBOLI, M.; FICHER, R. M.; CASADO, T. As pessoas na organização. 6 ed. São Paulo: Editora Gente, 2002.

FREITAS, A. L. P.; SOUZA, R. G. Um modelo para avaliação da qualidade de vida no

trabalho em universidades públicas, Revista Eletrônica Sistemas e Gestão, v. 4, n. 2, 136-154, 2009.

GARAY, L.; FONT, X. Doing good to do well? Corporate social responsibility reasons, practices and impacts in small and medium accommodation enterprises. International Journal of Hospitality Management, v. 31, p. 329-337, 2012.

GAULKE, C. N.; NICOLETI, G. G. Benefícios: usado como fator motivacional pela empresa Karsten S/A no setor tecelagem $1^{\circ}$ turno. Revista Interdisciplinar Científica Aplicada, v.1, n.2, p.1-15, 2007.

GIL, A. C. Gestão de Pessoas: enfoque nos papéis. São Paulo: Editora Atlas, 2007.

GOMES, A. A. P.; QUELHAS, O. L. G. Motivação dos recursos humanos no serviço Público: Um estudo de caso sob dois ângulos teóricos. Revista Eletrônica de Administração, v. 9, n. 5, p. 1-18, 2003. 
GUTIERREZ, G. L.; VILARTA, R. Qualidade de vida em propostas de intervenção corporativa. Campinas, SP: IPES Editorial, 2007.

HATZENBERGER, D. H. C.; CARLOTTO, M. S. Qualidade de vida e autocuidado em servidores públicos: prevenção e intervenção. In: ROSSI, A. M.; MEURS, J. A.; PERREWÈ, P. L. (Org.). Stress e qualidade de vida no trabalho: melhorando a saúde e o bem-estar dos funcionários. São Paulo: Atlas, p. 177-190, 2013.

INYANG, B. J.; AWA, H. O. A.; ENUOH, R.O. CSR-HRM Nexus: Defining the role engagement of the human resources professionals. International Journal of Business and Social Science, v. 2, n. 5, p. 118-126, 2011.

JAMALI, D. A Stakeholder approach to corporate social responsibility: a fresh perspective into theory and practice. Journal of Business Ethics, 82, p. 213-231, 2008.

LUEG, R.; PEDERSEN, M. M.; CLEMMENSEN, S. N. The role of corporate sustainability in a low-cost business model-A case study in the Scandinavian fashion industry. Business Strategy and the Environment, v. 24, n. 5, p. 344-359, 2015.

MARRAS, J. P. Gestão estratégica de pessoas: conceitos e tendências. São Paulo: Saraiva, 2010.

MATTEN, D.; MOON, J. "Implicit" and "explicit" CSR: a conceptual framework for a comparative understanding of corporate social responsibility. The Academy of Management

Review, v. 33, n. 2, p. 404-424, 2008.

MINZNER, A.; KLERMAN, J. A., MARKOVITZ, C. E.; FINK, B. The impact of capacity-building programs on nonprofits: a random assignment evaluation. Nonprofit and Voluntary Sector Quarterly, v. 43, n. 3, p. 547-569, 2014.

MOITINHO, G. C. Remuneração, benefícios e a retenção de talentos nas organizações. Revista Digital de Administração, v.1, n.1, p 1-8, 2011.

NETO, A, R.; MAZZA, A. C. A. A percepção dos gestores sobre as práticas de retenção de talentos adotadas em uma empresa de logística e distribuição. Revista Administração em Diálogo, v. 17, n. 1, p. 162-180, 2015.

PANDA, S.; MODAK, N. M.; CÁRDENAS-BARRÓN, L. E. Coordinating a socially responsible closed-loop supply chain with product recycling. International Journal of Production Economics, v. 188, p. 11-21, 2017.

PEDRO, N. M.; SEVERO, E. A.; CAPITANIO, R. P. R. A influência da motivação e ambiente de trabalho no clima organizacional: o caso de um centro administrativo de farmácias. In: SIMPÓSIO INTERNACIONAL DE INOVAÇÃO EM CADEIAS PRODUTIVAS DO AGRONEGÓCIO, 2, Vacaria, 2016. Anais... 
PFEFFER, J. Building sustainable organizations: the human factor. The Academy of Management Perspectives, v. 24, n. 1, p. 34-45, 2010.

RIBEIRO, L. A.; SANTANA, L. C. D. Qualidade de vida no trabalho: fator decisivo para o sucesso organizacional. RIC Cairu, v. 2, n. 2, p. 75-96, 2015.

RODRIGUES, A. L.; BARRICHELLO. A.; MORIN, E. M. Os sentidos do trabalho para profissionais de enfermagem: um estudo multimétodos. Revista de Administração Eletrônica, v. 56, n. 2, p 1-17, 2016.

SABADIN, R. K.; SEVERO, E. A.; GUIMARAES, J. C. F. Inovação em ergonomia, absenteísmo e risco no levantamento de carga. Desenvolve - Revista de Gestão do Unilasalle, v. 6, p. 31-51, 2017.

SANTOS, A. B. J.; SANTOS. B. G.; FERREIRA, C. N. S.; OLIVEIRA, M, S.; SOUZA, R. V. MENEZES, M. B. C. O papel dos benefícios e incentivos na satisfação do colaborador e nas estratégias das empresas. Cadernos de Graduação - Ciências Humanas e Sociais, v. 1, n.17, p.31-44, 2013.

SARTOR, M.; ORZES, G.; DI MAURO, C.; EBRAHIMPOUR, M.; NASSIMBENI, G. The SA8000 social certification standard: Literature review and theory-based research agenda. International Journal of Production Economics, v. 175, p. 164181, 2016.

SCHIRRMEISTER, R.; FRANÇA, A. C. L. A qualidade de vida no trabalho: relações com o comprometimento organizacional nas equipes multicontratuais. Revista Psicologia: Organizações e Trabalho, v. 12, n. 3, p. 283-298, 2012.

SILVA, C. E. G.; AGUIAR, A. C. Avaliação de atividades no terceiro setor de Belo Horizonte: da racionalidade subjacente às influências institucionais. Organização \& Sociedade, v. 18, n. 56, p. 35-56, 2011.

SOUZA, R..; FREITAS, A. Um modelo para avaliação da qualidade de vida no trabalho em universidades públicas. Sistemas e Gestão, v. 4, n. 2, p. 136-154, 2009.

SKUDIENE, V.; AURUSKEVICIENE, V. The contribution of corporate social responsibility to internal employee motivation. Baltic Journal of Management, v. 7, n. 1, p. 49-67, 2012.

TAMAYO, A.; PASCHOAL, T. A relação da motivação para o trabalho com as metas do trabalhador. Revista de Administração Contemporânea, v. 7, n. 4, p. 33-54, 2003.

TOLFO, S. R.; LUNA, I. N.; SILVA, N. Cultura organizacional, identidade e qualidade de vida no trabalho: articulações e sugestões de pesquisas em organizações. Pesquisa Práticas Psicossociais, v. 4, n. 1, p. 6-16, 2009. 
VASCONCELOS, K. C. A.; SILVA JUNIOR, A.; NASCIMENTO, A. P.; GOULART, V. $M$. A relação entre a percepção de práticas de responsabilidade social corporativa e a intenção de rotatividade dos profissionais. Revista de Administração de Empresas, v. 85, n. 3, p. 1-25, 2016.

VERGARA, S. C. Gestão de pessoas. 9 ed. São Paulo: Editora Atlas, 2010.

VISCAINO, C. C. L.; ESTORK, L. A. Gestão de pessoas: um olhar sobre a evolução histórica do principal ativo das organizações empresariais. Revista científica eletrônica de administração, v. 13, p. 1676-6822, 2007.

WALTON, R. E. Quality of work life: what is it? Sloan Management Review. Cambridge, v.15, n. 1, p. 11-21, 1973.

WOOD Jr, T.; PICARELLI, F. F. Remuneração estratégica. 3. ed, São Paulo: Atlas, 2004.

ZHU, Q.; LIU, J.; LAI, K-H. Corporate social responsibility practices and performance improvement among Chinese national state-owned enterprises. International Journal of Production Economics, v. 171, p. 417-426, 2016.

ZWIELEWSKI, G.; TOLFO, S. R. Qualidade de vida no trabalho de profissionais expatriados para Índia e China. Revista de Administração, v. 84, n.2, p. 510-542, 2016. 